\title{
Applying the wisdom of stepping down inhaled corticosteroids in patients with COPD: a proposed algorithm for clinical practice
}

This article was published in the following Dove Press journal:

International Journal of COPD

20 November 2015

Number of times this article has been viewed

\begin{abstract}
Alan G Kaplan ${ }^{1,2}$
'Family Physician Airways Group of Canada, ${ }^{2}$ Department of Family and Community Medicine, University of Toronto, Toronto, Ontario, Canada
\end{abstract}

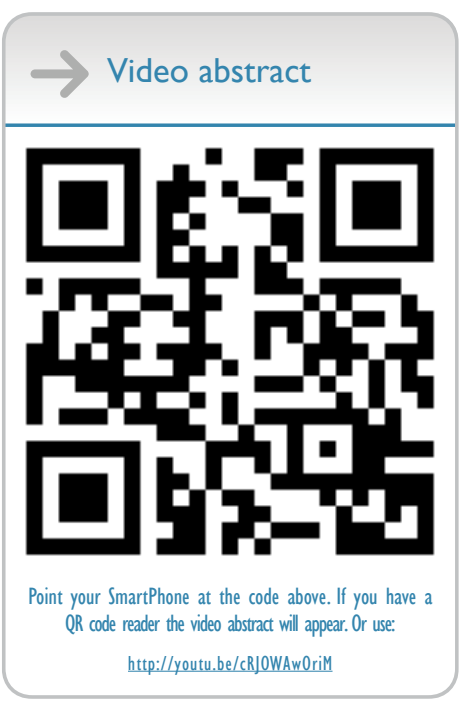

Correspondence: Alan G Kaplan Family Physician Airways Group of Canada, 17 Bedford Park Avenue, Richmond Hill, ON L4C 2N9, Canada $\mathrm{Tel}+\mathrm{I} 905883$ II 00

$\mathrm{Fax}+1905884$ II95

Email for4kids@gmail.com
Abstract: Current guidelines for the management of chronic obstructive pulmonary disease (COPD) recommend limiting the use of inhaled corticosteroids (ICS) to patients with more severe disease and/or increased exacerbation risk. However, there are discrepancies between guidelines and real-life practice, as ICS are being overprescribed. In light of the increasing concerns about the clinical benefit and long-term risks associated with ICS use, therapy needs to be carefully weighed on a case-by-case basis, including in patients already on ICS. Several studies sought out to determine the effects of withdrawing ICS in patients with COPD. Early studies have deterred clinicians from reducing ICS in patients with COPD as they reported that an abrupt withdrawal of ICS precipitates exacerbations, and results in a deterioration in lung function and symptoms. However, these studies were fraught with numerous methodological limitations. Recently, two randomized controlled trials and a real-life prospective study revealed that ICS can be safely withdrawn in certain patients. Of these, the WISDOM (Withdrawal of Inhaled Steroids During Optimized Bronchodilator Management) trial was the largest and first to examine stepwise withdrawal of ICS in patients with COPD receiving maintenance therapy of long-acting bronchodilators (ie, tiotropium and salmeterol). Even with therapy being in line with the current guidelines, the findings of the WISDOM trial indicate that not all patients benefit from including ICS in their treatment regimen. Indeed, only certain COPD phenotypes seem to benefit from ICS therapy, and validated markers that predict ICS response are urgently warranted in clinical practice. Furthermore, we are now better equipped with a larger armamentarium of novel and more effective long-acting $\beta_{2}$-agonist/long-acting muscarinic antagonist combinations that can be considered by clinicians to optimize bronchodilation and allow for safer ICS withdrawal. In addition to providing a review of the aforementioned, this perspective article proposes an algorithm for the stepwise withdrawal of ICS in real-life clinical practice.

Keywords: chronic obstructive pulmonary disease, inhaled corticosteroid, withdrawal, bronchodilation, clinical practice, algorithm

\section{Introduction}

While inhaled corticosteroid (ICS)-containing regimens benefit certain patients with chronic obstructive pulmonary disease (COPD), concerns about the inappropriate overuse of ICS in real-life practice, their clinical benefit and long-term risks, and considerable waste of health care resources that could be better used on other more appropriate management strategies prompted studies to evaluate whether certain patients already on ICS therapy fare better without it. ${ }^{1}$ This perspective paper explores the evidence available on ICS withdrawal in patients with COPD and the potential phenotypes that can be withdrawn from ICS therapy. Furthermore, an algorithm for 
clinical practice is proposed to address the following critical questions: 1) In which patients is ICS withdrawal safe? and 2) How to withdraw ICS in appropriate patients?

\section{Current guideline recommendations and real-life utilization of ICS in COPD}

Although ICS have been long used in the management of COPD, evidence supporting their use has been considered equivocal and their positioning in guidelines as controversial. According to the latest 2015 update of the Global Initiative for Chronic Obstructive Lung Disease (GOLD) report, ICS in combination with a long-acting $\beta_{2}$-agonist (LABA) and/or long-acting muscarinic antagonist (LAMA) is the first recommended choice for patients with a high-risk of exacerbations (Groups C and D; Figure 1). ${ }^{2}$ In addition to this international "gold standard" guideline, a number of national and multinational guidelines exist; however, their recommendations pertaining to the use of ICS are inconsistent with those of the GOLD report, in part, due to the varying criteria for categorizing patients with COPD and different interpretations of the equivocal evidence supporting

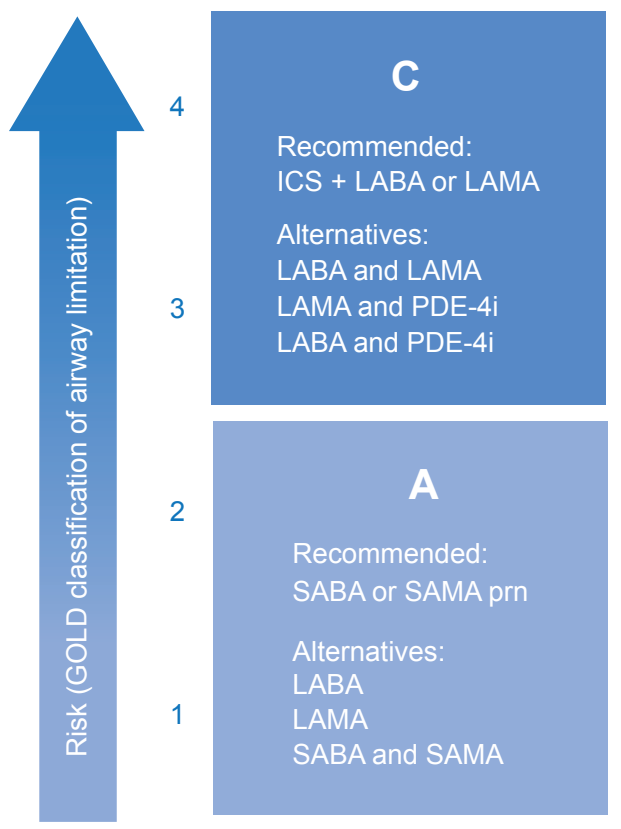

mMRC 0-1

CAT $<10$
ICS use. ${ }^{1,3-7}$ Despite this, there is consensus that ICS are indicated in combination with long-acting bronchodilators (LABDs) for patients with COPD at risk of exacerbations and/or in those with asthma-COPD overlap syndrome (ACOS), but never as monotherapy.

It is not surprising that there is a tremendous amount of confusion surrounding the use of ICS for the management of COPD in clinical practice. Several studies in multiple countries found discrepancies between guideline recommendations and real-life practice regarding ICS use in patients with COPD. ${ }^{8-10}$ In fact, ICS are being widely prescribed to the majority of patients with COPD, many of whom do not meet the recommendation criteria for ICS use (ie, 38.8\% and $51.8 \%$ of GOLD Groups A and B, respectively). ${ }^{10}$ Market research estimates suggest that ICS are used by $>70 \%$ of patients with COPD, and given as initial therapy to $>50 \%$ of newly diagnosed patients, mostly in combination with a LABA. ${ }^{11}$ These high real-world utilization rates are also corroborated by the treatment profiles of patients entering recent randomized controlled trials (RCTs), where $\sim 35 \%$ of patients classified into either GOLD Group A or B were receiving ICS at baseline. ${ }^{12,13}$

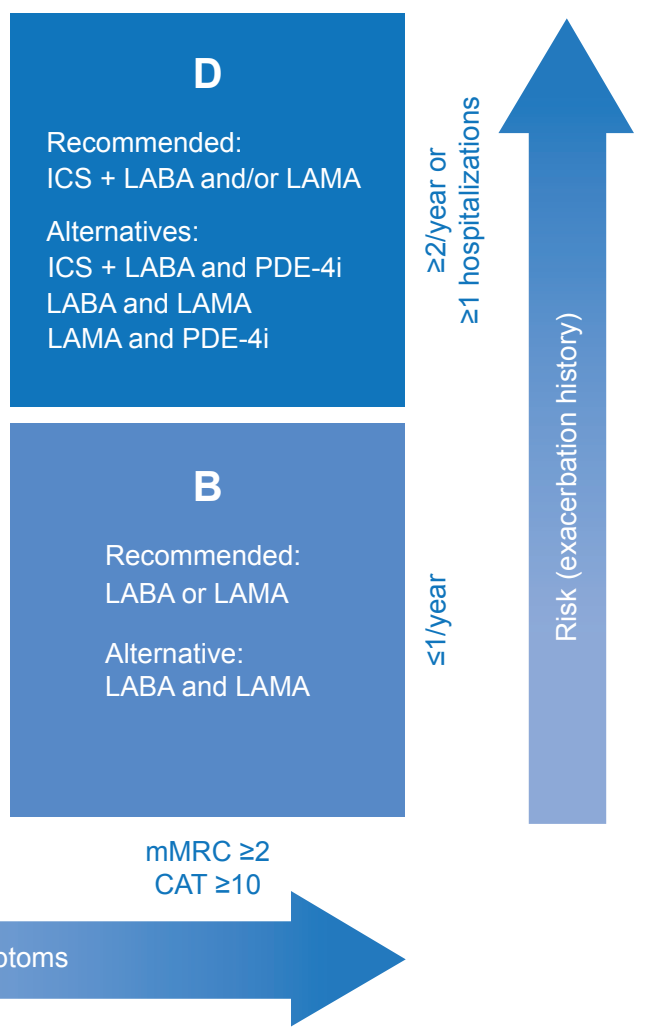

Figure I GOLD recommendations for the pharmacologic management of stable COPD according to the four GOLD groups of COPD, which are based on a combined assessment of symptoms and exacerbation risk.

Note: Adapted by the author from the Global Strategy for Diagnosis, Management and Prevention of COPD 20I5, @ Global Initiative for Chronic Obstructive Lung Disease (GOLD), all rights reserved. Available from http://www.goldcopd.org. ${ }^{2}$

Abbreviations: CAT, COPD Assessment Test; COPD, chronic obstructive pulmonary disease; GOLD, Global Initiative for Chronic Obstructive Lung Disease; ICS, inhaled corticosteroids; LABA, long-acting $\beta_{2}$-agonist; LAMA, long-acting muscarinic antagonist; mMRC, modified Medical Research Council Dyspnea Scale; PDE-4i, phosphodiesterase-4 inhibitor; prn, as needed; SABA, short-acting $\beta_{2}$-agonist; SAMA, short-acting muscarinic antagonist. 


\section{Evidence for the use of ICS in COPD: is there a benefit?}

The introduction of ICS in the management of COPD was rather unorthodox and unsubstantiated for nearly 20 years (summarized in Table 1 and previously reviewed in detail elsewhere). ${ }^{1,11,14,15}$ Briefly, in the 1980s, ICS were adopted in COPD on the basis of their effectiveness in asthma rather than scientific evidence. ${ }^{11,16}$ The earliest RCTs of ICS therapy in

Table I History of evidence for the use of ICS-containing treatment regimens in COPD

\begin{tabular}{|c|c|c|}
\hline Timeline & Intervention & Evidence \\
\hline 1980s & $\mathrm{N} / \mathrm{A}$ & $\begin{array}{l}\text { - ICS were adopted in the management of COPD based on the fact that they were highly effective in } \\
\text { asthma rather than scientific evidence" }\end{array}$ \\
\hline $\begin{array}{l}\text { Late } \\
1990 \text { s }\end{array}$ & ICS alone & $\begin{array}{l}\text { - Early RCTs in patients with mild COPD (ie, FEV, near } 80 \% \text { predicted) found no improvement in the } \\
\text { decline of lung function over time and no reduction in the exacerbation rate with various ICS compared } \\
\text { with placebo }{ }^{11,15,17,18}\end{array}$ \\
\hline 2000 & ICS alone & $\begin{array}{l}\text { - ISOLDE was the first trial to demonstrate the beneficial effects of ICS (ie, fluticasone propionate) on } \\
\text { exacerbation rate in patients with moderate-to-severe COPD (ie, FEV, } \leq 50 \% \text { predicted); albeit, there was } \\
\text { no effect on the rate of decline in lung function }{ }^{19} \\
\text { - The Lung Health Study, which also included patients with lower FEV (mean } 56 \% \text { predicted), found that } \\
\text { patients treated with an ICS (ie, triamcinolone) reported fewer visits to a physician for respiratory illness }{ }^{73}\end{array}$ \\
\hline 2001 & ICS alone & $\begin{array}{l}\text { - In a large population-based cohort study of } 22,620 \text { patients with COPD who were previously hospitalized, } \\
\text { it was found that patients who received ICS within } 90 \text { days postdischarge had } 24 \% \text { fewer rehospitalizations } \\
\text { and a } 29 \% \text { risk reduction for mortality during a I-year follow-up }{ }^{20}\end{array}$ \\
\hline 2002 & $\begin{array}{l}\text { ICS alone } \\
\text { ICS + LABA }\end{array}$ & $\begin{array}{l}\text { - A meta-analysis of early RCTs reported a significant } 30 \% \text { overall reduction in exacerbations with } \mathrm{ICS}^{74} \\
\text { - RCTs began evaluating ICS in combination with a LABA (ie, either budesonide/formoterol or fluticasone } \\
\text { propionate/salmeterol) })^{11,21,22}\end{array}$ \\
\hline 2007 & $\mathrm{ICS}+\mathrm{LABA}^{\mathrm{a}}$ & $\begin{array}{l}\text { - In the landmark TORCH trial, a } 3 \text {-year, randomized, double-blind trial comparing salmeterol plus } \\
\text { fluticasone propionate vs placebo, salmeterol alone, or fluticasone propionate alone in patients with } \\
\text { COPD (FEV },<60 \% \text { of predicted), it was found that: }{ }^{22} \\
\text { O There was no significant benefit of ICS + LABA on all-cause mortality (primary end point); however, the } \\
\text { statistical significance was borderline when compared with placebo }(I 7.5 \% \text { reduction; } P=0.052) \\
\text { ICS + LABA significantly reduced the rate of exacerbations vs placebo (by } 25 \%, P<0.00 \mathrm{I}) \text { and LABA or } \\
\text { ICS alone }(I 2 \%, P=0.002 \text { and } 9 \%, P=0.024 \text {, respectively) } \\
\text { ICS + LABA had a much slower rate of decline in lung function compared with placebo }(P \leq 0.003) \text { and } \\
\text { LABA or ICS alone }(P<0.00 \text { I, respectively) } \\
\text { ICS + LABA significantly improved health status vs placebo, LABA, or ICS alone }(P<0.00 \text { I for all) }\end{array}$ \\
\hline & $\begin{array}{l}\text { Adding ICS + LABA } \\
\text { to LAMA }\end{array}$ & $\begin{array}{l}\text { - The Canadian Optimal trial was a I-year, randomized, double-blind, placebo-controlled study that } \\
\text { evaluated the addition of ICS + LABA (fluticasone propionate/salmeterol), LABA, or placebo in } 449 \\
\text { patients with moderate-to-severe COPD who were receiving LAMA (tiotropium) } \\
\text { The findings of this trial were conflicting in that the addition of ICS + LABA to LAMA did not } \\
\text { statistically influence rates of COPD exacerbation, but did improve lung function, quality of life, and } \\
\text { hospitalization rates }\end{array}$ \\
\hline 2008 & $\mathrm{ICS}+\mathrm{LABA}$ vs $\mathrm{LAMA}^{\mathrm{a}}$ & $\begin{array}{l}\text { - The INSPIRE trial, a 2-year, randomized, double-blind, double-dummy parallel study, directly compared } \\
\text { ICS + LABA (fluticasone propionate/salmeterol) and LAMA (tiotropium) in a total of I,323 patients with } \\
\text { severe COPD, and was the first to show that there was no difference in exacerbation rate between ICS + } \\
\text { LABA and LAMA }{ }^{24}\end{array}$ \\
\hline 2009 & $\mathrm{ICS}+\mathrm{LABA}+\mathrm{LAMA}^{\mathrm{b}}$ & $\begin{array}{l}\text { - In the CLIMB trial, a I2-week, randomized, double-blind, parallel-group, multicenter study, the efficacy } \\
\text { and tolerability of adding a LAMA (tiotropium) to ICS + LABA (budesonide/formoterol) vs placebo was } \\
\text { assessed in } 660 \text { patients with COPD after a } 2 \text {-week run-in period }{ }^{76} \\
\text { The addition of ICS + LABA to a LAMA vs LAMA alone reduced severe exacerbations (by } 62 \% \text {; } \\
P<0.00 \text { I), as well as provided a rapid and sustained improvement in lung function }(P<0.00 \text { I), health } \\
\text { status, and symptoms }\end{array}$ \\
\hline 2015 & $\mathrm{ICS}+\mathrm{LABA}$ & $\begin{array}{l}\text { - In the SUMMIT trial, a placebo-controlled, double-blind, randomized, parallel group, multicenter study, } \\
\text { mortality risk on ICS + LABA (fluticasone furoate/vilanterol) was evaluated in } 16,485 \text { patients from } 43 \\
\text { countries who had COPD with moderate airflow limitation (FEV, } 50 \%-70 \% \text { predicted) and either a } \\
\text { history or risk of cardiovascular disease }{ }^{26} \\
\text { Risk of mortality was found to be } 12.2 \% \text { lower with ICS + LABA compared with placebo; albeit, this } \\
\text { difference was not statistically significant }(P=0.137)\end{array}$ \\
\hline
\end{tabular}

Notes: aUsed as evidence to support recommendations for GOLD Group C. bUsed as evidence to support recommendations for GOLD Group D despite concerns about conflicting findings and/or short-term duration of trials.

Abbreviations: COPD, chronic obstructive pulmonary disease; FEV , forced expiratory volume in I second; GOLD, Global Initiative for Chronic Obstructive Lung Disease; ICS, inhaled corticosteroids; INSPIRE, Investigating New Standards for Prophylaxis in Reduction of Exacerbations; ISOLDE, Inhaled Steroids in Obstructive Lung Disease in Europe; LABA, long-acting $\beta_{2}$-agonist; LAMA, long-acting muscarinic antagonist; N/A, not applicable; RCT, randomized controlled trial; SUMMIT, Study to Understand Mortality and MorbidITy in COPD; TORCH, TOwards a Revolution in COPD Health. 
mild COPD were conducted in the late 1990s; however, their outcomes were negative. ${ }^{11,15,17,18}$ ISOLDE (Inhaled Steroids in Obstructive Lung Disease in Europe) was the first trial to demonstrate a beneficial effect of ICS on the occurrence of exacerbations in patients with moderate-to-severe COPD; albeit, no benefit on the rate of lung function decline was observed. ${ }^{19}$ In 2001, a large population-based cohort study of 22,620 patients with COPD and a very recent hospitalization found that those who received ICS within 90 days postdischarge had 24\% fewer rehospitalizations and a $29 \%$ risk reduction for mortality during a 1-year follow-up. ${ }^{20}$ Although these findings are not definitive due to their observational nature, they suggest that patients who have had a hospitalization in the past year should continue receiving ICS. From 2002 onward, the subsequent cohort of RCTs began evaluating ICS in combination with LABDs. ${ }^{11,21,22}$

In the landmark TORCH (TOwards a Revolution in COPD Health) trial, it was found that ICS plus a LABA (ICS + LABA) resulted in significantly fewer exacerbations, slower rate of decline in lung function, and improved health status; however, there was only a trend toward improved survival. ${ }^{22}$ These findings formed the initial basis for the inclusion of ICS-containing treatment regimens in clinical guidelines. ${ }^{2,11}$ At this time, the importance of exacerbations as a key determinant of health status and its association with a faster decline in lung function was being recognized, and the prevention of exacerbations became a key objective of COPD management. ${ }^{16}$ Of note, a post hoc analysis of the TORCH data, which evaluated the independent contribution of ICS and LABA, found that the benefits of ICS + LABA were actually provided by the LABA. ${ }^{1,15,23}$ Soon after TORCH, the INSPIRE (Investigating New Standards for Prophylaxis in Reduction of Exacerbations) trial was the first to show that ICS + LABA was no more effective than a LAMA in preventing exacerbations in patients with severe COPD, which initiated the discussion of whether adding ICS to LABDs is beneficial. ${ }^{24}$ Indeed, a recent Cochrane meta-analysis questioned the superiority of ICS + LABA combinations over LABA alone in preventing exacerbations. ${ }^{25}$ Lastly, the findings of the SUMMIT (Study to Understand Mortality and MorbidITy in COPD) trial were recently presented at the 2015 European Respiratory Society Congress. ${ }^{26}$ The SUMMIT trial to evaluate the impact of a once-daily ICS + LABA (fluticasone furoate/ vilanterol) versus the monocomponents on the survival of 16,485 patients with moderate COPD and either a history or increased risk of cardiovascular disease (CVD). After a 44-month follow-up, it was found that the risk of mortality on ICS + LABA was $12.2 \%$ lower than on placebo over the study period; however, this difference was not statistically significant $(P=0.137)$. While the findings of the TORCH trial suggested that ICS + LABA may reduce mortality in patients with COPD, particularly those with CVD risk, no study to date has been able to demonstrate a benefit. ${ }^{22,26}$

\section{What are the risks associated with ICS?}

A number of local and systemic adverse events have been associated with ICS, particularly with long-term and highdose use. ${ }^{1,15}$ The local adverse events include pneumonia, ${ }^{27,28}$ oropharyngeal candidiasis, ${ }^{29}$ and tuberculosis, ${ }^{30,31}$ and the systemic adverse events include cataracts, ${ }^{32,33}$ glaucoma, ${ }^{15}$ osteoporosis and bone fractures, ${ }^{34}$ easy bruising, ${ }^{18}$ type 2 diabetes, ${ }^{35}$ and even cases of adrenal suppression. ${ }^{36}$ While there have always been concerns about the risks of developing osteoporosis, cataracts, and diabetes in patients with COPD, risk of pneumonia is arguably the most notable and well-established adverse event associated with ICS use in COPD, as supported by consistent evidence from RCTs. ${ }^{1,14,15,24,27,37}$ Corroborating this, a recent Canadian population-based cohort study of 103,386 patients with COPD who were treated with ICS demonstrated that discontinuation of ICS was associated with a $37 \%$ reduction in the risk of serious pneumonia. ${ }^{38}$ Indeed, in the latest update of the GOLD report, it is cautioned that long-term ICS-containing treatment should not be prescribed outside their indication due to risk of pneumonia and the possibility of a slight increased risk of fractures following long-term exposure. ${ }^{2}$ As patients with COPD are more likely to be older and often have several comorbidities for which they receive multiple medications, they are more susceptible to ICS-associated adverse events, and their potential risks need to be weighed against the likely benefits on a case-by-case basis, even in those already on ICS. ${ }^{1}$ Given the concerns about the risk-benefit profile of ICS, there has been a renewed interest in reevaluating the role of ICS in COPD and identifying which patients can be managed as well with alternate therapies. ${ }^{37}$

\section{Evidence regarding ICS withdrawal}

Early observational studies and RCTs investigating the implications of ICS withdrawal in patients with COPD found that an abrupt cessation of ICS therapy precipitates exacerbations, and results in a deterioration in lung function, symptoms, and health status (summarized in Table 2). ${ }^{39-44}$ However, a meta-analysis of three of these RCTs (ie, COPE, COSMIC [COPD and Seretide: a Multi-center Intervention 


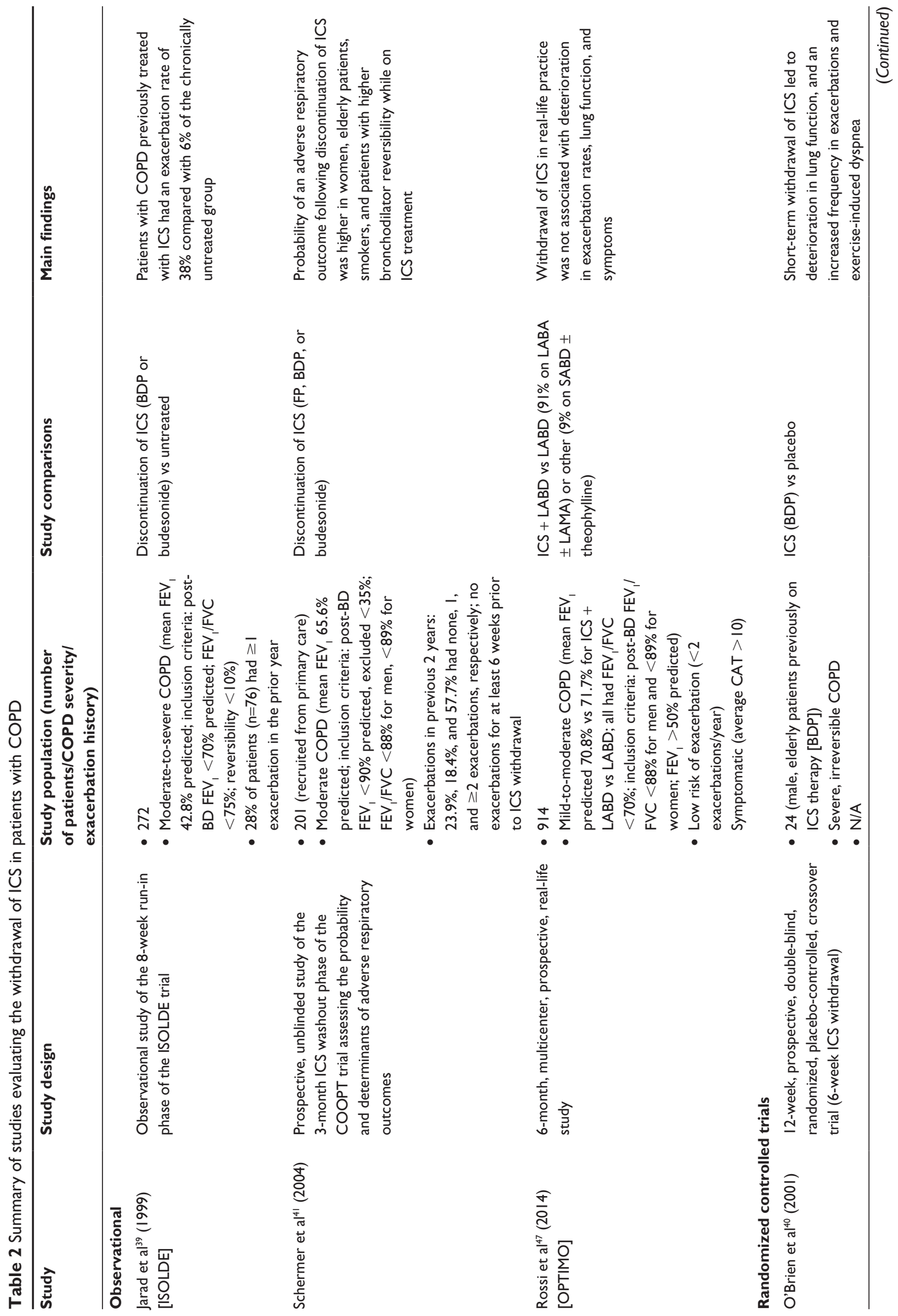




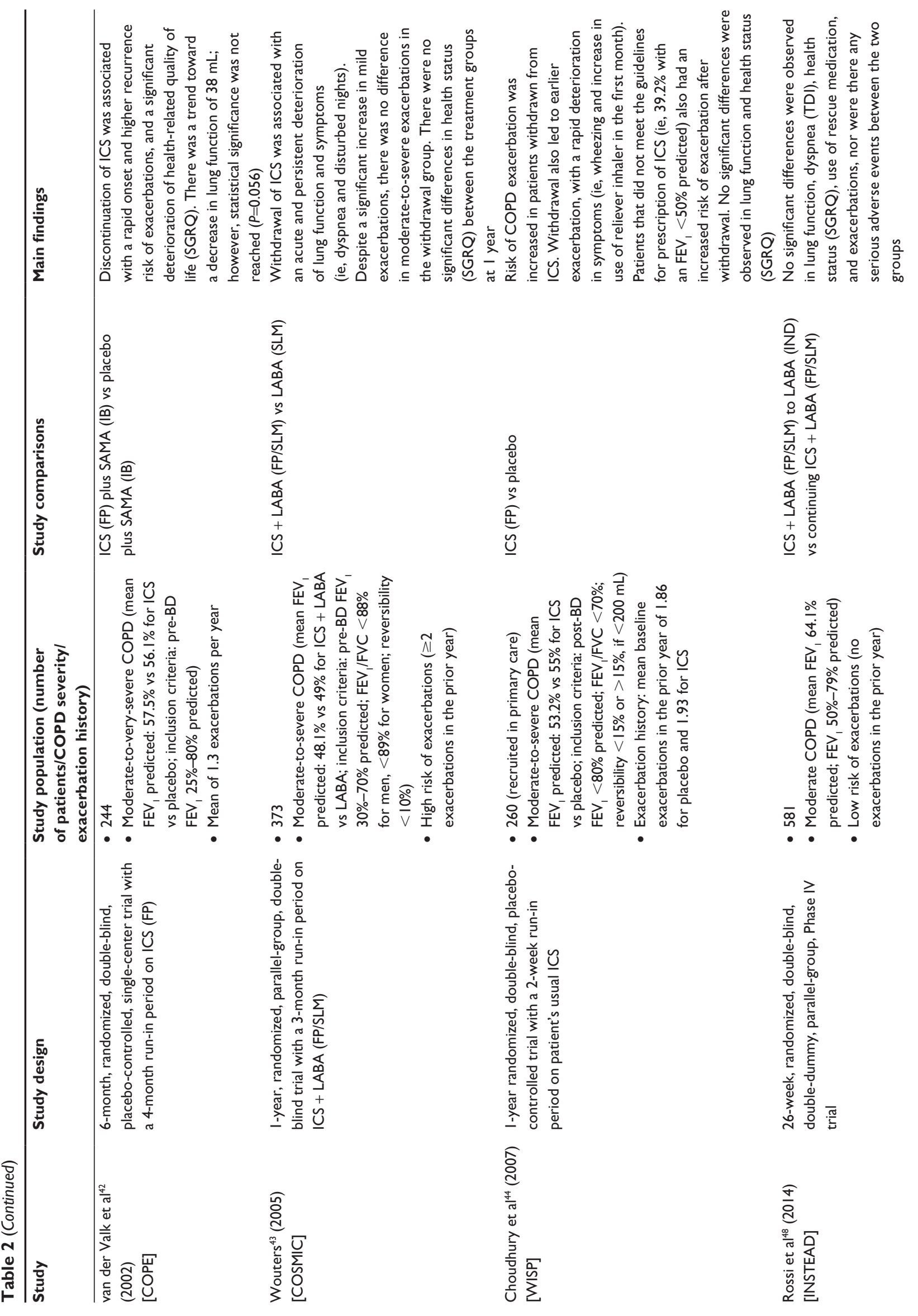



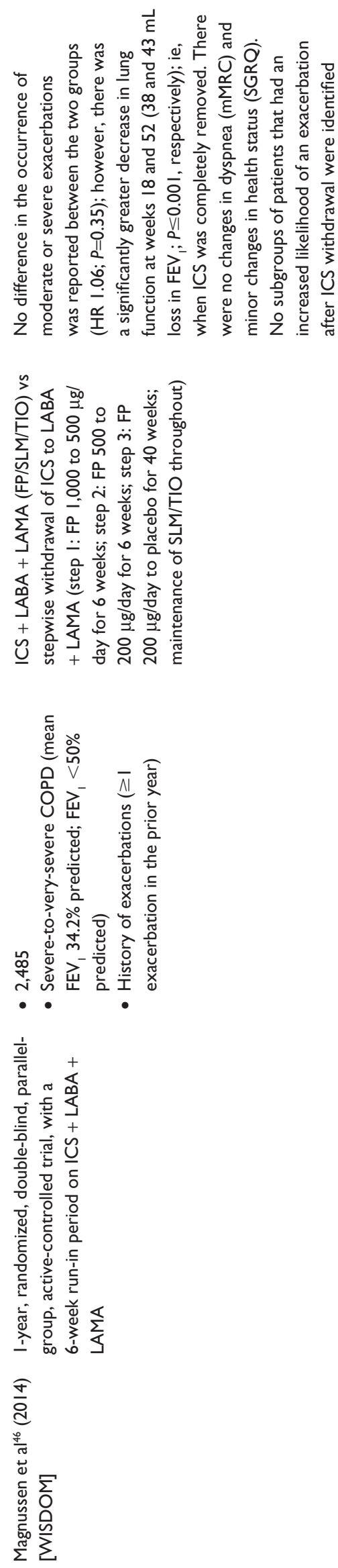

and Characterization], and WISP), the only trials deemed to be acceptable in terms of quality and level of bias, determined that withdrawal of ICS was not associated with any statistically significant increase in the exacerbation rate, and that the effects on other outcomes, such as lung function and health status, were inconclusive. ${ }^{45}$ The contradictory findings of these studies may be due to a number of methodological issues, including heterogeneity in patients' characteristics, disease severity, outcome definitions (eg, exacerbations), concomitant treatments (eg, run-in period treatment, maintenance with LABDs vs placebo), and setting (ie, primary vs secondary care). ${ }^{45,46}$ Of note, since patient inclusion in all trials was based on spirometry while receiving ICS therapy, this does not rule out a diagnosis of concomitant asthma, even if spirometry was of no significant reversibility. ${ }^{42-44}$ Additionally, in COSMIC, the forced expiratory volume in 1 second $(\mathrm{FEV}$,$) / forced vital capacity ratios used do not match the$ diagnostic criteria for COPD (ie, $<70 \%$ ), suggesting that these patients may have had an asthma component, and thereby, cessation of ICS could have been detrimental., ${ }^{2,43}$

According to the latest GOLD recommendations, patients with COPD and a low risk of exacerbations should not be prescribed ICS-containing regimens. ${ }^{2}$ Given that a large proportion of patients are already initiated on such regimens, it would be helpful to know if there are consequences associated with ICS withdrawal in such populations (ie, GOLD Groups A and B). Recently, in the first real-life prospective study (OPTIMO [Real-Life study On the aPpropriaTeness of treatment in MOderate COPD patients]), it was demonstrated that withdrawal of ICS in patients with symptomatic, moderate COPD (ie, $\mathrm{FEV}_{1}>50 \%$ predicted) at a low risk of exacerbations (ie, $<2 /$ year) was not associated with any deterioration in lung function, symptoms, and exacerbation rate over a 6 -month observation period. ${ }^{47}$ These findings were further confirmed by the recent INSTEAD (Indacaterol: Switching Non-exacerbating Patients with Moderate COPD from Salmeterol/Fluticasone to Indacaterol) trial, the first RCT with a clearly defined patient population with moderate COPD (ie, FEV, $50 \%-80 \%$ predicted) and no prior exacerbation history, which found that switching from a fixed-dose combination of ICS + LABA to a LABA was not associated with any differences in lung function, symptoms, health status, and exacerbations. ${ }^{48}$ In addition to supporting the current GOLD recommendations (ie, no need for ICS in Groups A and B), the results from both studies suggest that ICS therapy can be safely withdrawn from patients with moderate COPD and a low risk of exacerbations provided that they are left on maintenance treatment with LABDs. 
In all studies to date, withdrawal of ICS has been abrupt. It is well known that an abrupt cessation of chronic corticosteroid therapy precipitates rebound systemic effects due to steroid withdrawal symptoms. ${ }^{11,46}$ Currently, there is no clear evidence on whether abrupt ICS withdrawal is safe; however, similar to the approach used to downtitrate ICS in patients with asthma, a stepwise withdrawal of ICS may minimize the potential risk of rebound steroid effects. ${ }^{11,46,49}$

Adding to the growing clinical evidence-base on the impact of ICS withdrawal against a background of LABDs, the WISDOM (Withdrawal of Inhaled Steroids During Optimized Bronchodilator Management) trial, which is larger than all of the previous ICS withdrawal RCTs combined, was the first to assess the question of whether a stepwise withdrawal of ICS on top of maintenance therapy with dual bronchodilation (tiotropium/salmeterol) had a similar risk of exacerbations in patients with COPD and a history of exacerbations (ie, GOLD Groups C and D, in whom GOLD recommendations support the addition of ICS to LABD therapy). ${ }^{2,46,50}$ In this, 12-month, randomized, double-blind, parallel-group, active-controlled trial, 2,485 patients with COPD and a history of exacerbations received triple therapy (ie, fluticasone propionate/tiotropium/salmeterol) during a 6-week run-in period. Afterward, patients were randomized to either continue or withdraw ICS therapy. In the ICS withdrawal group, the dose of ICS was gradually reduced by approximately half in a stepwise fashion every 6 weeks, such that after 12 weeks, ICS was completely withdrawn. It was found that there was no difference in the occurrence of moderate or severe exacerbations between the two groups. ${ }^{50}$ Additionally, subgroup analyses revealed no notable differences in the occurrence of exacerbations based on age, sex, smoking status, body mass index, ICS or $\beta$-blocker therapy at screening, chronic bronchitis, GOLD stage and group, and prior therapy with antibiotics or systemic glucocorticoids. While there was a small, but significant, reduction in lung function when ICS was completely withdrawn, the clinical importance of this is unclear. Taken together, these findings suggest that even patients with severe COPD and a high-risk of exacerbations can be safely withdrawn from ICS therapy as long as they are clinically stable and maintained on a background of LABDs. Even with ICS use being in line with the GOLD recommendations, the WISDOM results also indicate that not all patients with severe-to-very-severe COPD seem to benefit from including ICS in their treatment regimen.

With the intent of identifying potential markers of ICS responsiveness, a substudy on $\sim 500$ patients was also performed in the WISDOM trial. ${ }^{46}$ These patients were evaluated for emphysema, bronchiectasis, diffusing capacity for carbon monoxide, and the following biomarkers: adiponectin, leptin, C-reactive protein, interleukin-6, interleukin-8, tumor necrosis factor- $\alpha$, fibrinogen, soluble interleukin adhesion molecule-1, serum amyloid $\mathrm{A}$, procalcitonin, and B-type natriuretic peptide. Airway inflammation through differential cell count in sputum and fraction of exhaled nitric oxide (FeNO) was also assessed. Unfortunately, no subgroups or biomarkers were found to be associated with an increased likelihood of exacerbations after ICS withdrawal; ${ }^{46,51}$ albeit, certain phenotypes and potential biomarkers that have been previously shown to be associated with ICS responsiveness were not evaluated (discussed in the next section). ${ }^{16}$

\section{COPD phenotypes: which patients benefit from ICS?}

Because COPD is a complex and heterogeneous disease with several different pathophysiological mechanisms, it is likely that ICS may have an effect on some components of the disease, particularly when airway inflammation is present. ${ }^{11,15}$ Increasing evidence suggests that patients with certain COPD phenotypes appear to benefit from ICS treatment, including patients with ACOS, frequent exacerbators, and those with eosinophilia. ${ }^{1,6,15,52}$

ACOS was only formally recognized by the Global Initiative for Asthma (GINA) and GOLD for the first time in 2014. It has been estimated that ACOS occurs in up to $25 \%$ of patients with COPD; however, establishing its prevalence has been difficult because there is no universally accepted definition for this syndrome. ${ }^{1,52-56}$ According to the GINA/ GOLD Consensus Statement, ACOS is characterized by persistent airflow limitation and identified by the features that it shares with both asthma and COPD.${ }^{56}$ In addition to having a history or clinical features of asthma, the presence of a large bronchodilator response (ie, $>12 \%$ and $400 \mathrm{~mL}$ ) and eosinophilic inflammation may also point to ACOS in patients with persistent airway obstruction. ${ }^{15,56}$ Due to the presence of an asthma component, patients with ACOS are likely to benefit from ICS therapy. Recently, a large observational study reported a survival benefit in patients with COPD starting on ICS + LABA compared with LABA alone; however, this survival benefit was only observed in those who had a codiagnosis of asthma. ${ }^{57}$

Frequent exacerbators account for approximately one-third of patients with COPD..$^{52,58}$ The definition of an exacerbator is based on expert opinion rather than rigorous 
phenotypic assessment, with a history of exacerbations being the best predictor of exacerbations across all GOLD stages. ${ }^{2}$ In the current GOLD report, exacerbation risk is based on either GOLD classification of airway limitation or history of exacerbations (ie, high exacerbation risk is defined as $\geq 2$ exacerbations per year or $\geq 1$ hospitalization); however, not all patients with moderate-to-severe COPD (ie, GOLD Groups $\mathrm{C}$ and D) are necessarily exacerbators, and therefore, require ICS. ${ }^{2,59}$ Indeed, in a 26-week, randomized, doubleblind, parallel-group trial of patients with moderate-tosevere COPD and no history of exacerbations, it was found that dual bronchodilation (ie, LABA + LAMA) provided significantly better and clinically relevant improvements in lung function versus ICS + LABA. ${ }^{12}$ The findings from the ENERGITO trial, which were recently reported at the 2015 European Respiratory Society Congress, further corroborate this point. ${ }^{60}$ In this randomized, double-blind, doubledummy, four-period crossover trial, lung function was evaluated in patients with moderate-to-severe COPD after treatment with LABA + LAMA (ie, tiotropium/olodaterol) versus ICS + LABA (ie, fluticasone propionate/salmeterol). After 6 weeks of treatment, it was found that LABA + LAMA significantly improved lung function compared with ICS + LABA. Thus, subclassification within GOLD Groups $\mathrm{C}$ and D may be warranted to take into account nonexacerbators. To complicate matters further, while both history of exacerbations and COPD severity are risk factors for repeat exacerbations, there are a number of other risk factors associated with repeat exacerbations that should be considered, including eosinophilic inflammation, comorbidities and extrapulmonary manifestations (eg, CVD, anxiety, depression, myopathy, reflux disease), chronic bronchitis, and increasing age. ${ }^{6}$

Lastly, it has been suggested that up to $30 \%$ of patients with COPD have eosinophilia. ${ }^{16,61}$ Eosinophilia has been suggested to be predictive of exacerbations in patients with mild-to-moderate COPD following withdrawal of ICS, ${ }^{62}$ and both sputum and blood eosinophil levels have been shown to be promising biomarkers of ICS responsiveness in patients with COPD. ${ }^{63,64}$ In one RCT, a management strategy for patients with COPD that suppressed sputum eosinophil levels $\leq 3 \%$ was found to reduce severe exacerbations. ${ }^{64}$ Although it has been suggested that sputum eosinophil levels may be the most reliable predictor of ICS responsiveness in patients with COPD to date, obtaining sputum samples is technically demanding and not feasible in routine clinical practice. ${ }^{15}$ Since there is a reasonable correlation between sputum and blood levels, blood eosinophil levels may offer a more practical alternative. ${ }^{63}$ Consequently, blood eosinophil levels are currently a topical issue and defining the appropriate cutoff for determining ICS responsiveness in patients with COPD is a subject of intense discussion. In a recent post hoc analysis of two replicate, 12-month, double-blind RCTs comparing a LABA with ICS + LABA in a total of 3,177 patients with moderate-to-severe COPD and a history of $\geq 1$ exacerbation, it was found that across all doses of ICS, ICS + LABA significantly reduced exacerbations by $29 \%$ versus LABA alone in patients with blood eosinophil levels of $\geq 2 \%{ }^{63}$ Conversely, in another post hoc analysis of two replicate, 26-week, double-blind, double-dummy, parallel-group RCTs, an absolute blood eosinophil cutoff of $>300$ cells $/ \mathrm{mm}^{3}$ at baseline as opposed to a percent cutoff appeared to best differentiate patients with moderate-to-severe COPD who benefited from ICS + LABA versus LABA + LAMA therapy in terms of reduction in exacerbation risk. ${ }^{65}$ This observation was corroborated by another post hoc analysis of the randomized, double-blind, parallel-group FORWARD (FOsteR 48-week trial to reduce exAceRbations in COPD) trial, which concluded that a greater reduction in exacerbations was observed when ICS was added to a LABA in patients with severe COPD and a history of exacerbations who had an eosinophil count $\geq 279.8$ cells $/ \mathrm{mm}^{3}{ }^{36}$ Using an absolute as opposed to a percent cutoff was further supported by the findings of the Copenhagen General Population Study, which evaluated 7,225 patients with COPD over a median follow-up of 3.3 years and found that an absolute blood eosinophil count of $\geq 340$ cells $/ \mathrm{mm}^{3}$ was a better predictor of both moderate and severe exacerbation risk than a percent cutoff of $2 \%{ }^{67}$ Accordingly, $\geq 300$ cells $/ \mathrm{mm}^{3}$ can be tentatively used as a cutoff until this value is further validated in prospective trials. Meanwhile, it will suffice to recognize that blood eosinophil counts can be easily measured in clinical practice as they are more accessible than sputum eosinophil levels.

In addition to eosinophil levels, it has been suggested that FeNO levels can be used as a surrogate marker of eosinophilic inflammation in patients with COPD exacerbations. ${ }^{68,69}$ A recent review on ACOS suggested the following FeNO levels for comparing between patients with asthma, ACOS, and COPD: $>50,25-50$, and $<25 \mathrm{ppb}$, respectively. ${ }^{55}$ These cutoffs are in line with the 2011 American Thoracic Society FeNO guidelines, which suggest that $\mathrm{FeNO}<25$ ppb provides a strong indication for an unlikely ICS response and $\mathrm{FeNO}>50 \mathrm{ppb}$ provides a strong indication for a likely ICS response, but FeNO between 25 and 50 ppb should be interpreted with caution. ${ }^{70,71}$ 


\section{Safely withdrawing ICS from patients with COPD: a proposed algorithm for clinical practice}

Since there is an overall paucity of evidence about when and how ICS can be safely withdrawn, the criteria for continuing or withdrawing ICS in patients with COPD are uncertain and more studies are warranted to characterize patients in whom withdrawal is safe. In a recent Spanish consensus document on the appropriate use of ICS in COPD, a panel of 25 experts voted on statements developed by a coordinator group that systematically reviewed scientific evidence on the efficacy and safety of ICS, and criteria for ICS withdrawal. ${ }^{52}$ Consensus was reached on the following statements concerning ICS withdrawal: withdrawal of ICS in COPD is feasible, patients who discontinue ICS should be evaluated in the short-term, and ICS withdrawal should be tapered. ICS withdrawal was thought to be possible if there is no evidence of ACOS, no exacerbations in the previous 2 years, and, with a lower level of agreement, in the absence of a positive bronchodilator test and decline after switching from high to low ICS doses. However, it should be kept in mind that these criteria are based on expert opinion and need to be validated in RCTs. Of note, there were also a significant number of statements for which it was difficult to reach a consensus, thereby identifying several areas of uncertainty.

Currently, no national or international clinical guidelines advocate withdrawal of ICS nor do they provide recommendations regarding the safe withdrawal of ICS in patients with COPD. For reasons previously described, there is an urgent need for a step-by-step algorithm that can be applied in reallife clinical practice. Figure 2 proposes such an algorithm and attempts to address the following questions: 1) In which patients is ICS withdrawal safe? and 2) How to withdraw ICS in appropriate patients? This algorithm takes into account not only exacerbation risk, as per GOLD, but also the emerging, neglected ACOS phenotype, as per the GINA/GOLD Consensus Statement. Potential markers of eosinophilia are also considered and noted as optional, as these are still theoretical and need to be tested in RCTs. Furthermore, the stepwise ICS withdrawal protocol on top of maintenance therapy with dual bronchodilation is primarily based on the WISDOM trial, although, instead of down-titrating ICS every 6 weeks, it is proposed that physicians consider stepping down ICS dose every 6-12 weeks. The rationale for this is to ensure that the effects of ICS in the inflammation cascade of COPD have been optimized on a physiological level, ${ }^{72}$ and from a practical perspective, permit enough time to monitor for potential exacerbations. In regards to optimizing bronchodilation
Table 3 LABA + LAMA combinations currently available or in development

\begin{tabular}{ll}
\hline LABA + LAMA combinations $^{\mathbf{a}}$ & Company \\
\hline Available & \\
$\begin{array}{l}\text { Aclidinium/formoterol } \\
\text { Glycopyrronium/indacaterol }\end{array}$ & $\begin{array}{l}\text { AstraZeneca (London, UK) } \\
\text { Tiotropium/olodaterol }\end{array}$ \\
$\begin{array}{l}\text { Boehringer Ingelheim (Ingelheim, } \\
\text { Germany) }\end{array}$ \\
$\begin{array}{l}\text { Umeclidinium/vilanterol } \\
\text { In development }\end{array}$ \\
Glycopyrronium/formoterol & AstraZeneca (London, UK) \\
\hline
\end{tabular}

Note: aln alphabetical order.

Abbreviations: LABA, long-acting $\beta_{2}$-agonist; LAMA, long-acting muscarinic antagonist.

following ICS withdrawal, we are now more equipped than ever before with a larger armamentarium of novel LABA + LAMA combinations that clinicians can consider for more effective bronchodilation maintenance (Table 3).

Lastly, it is fully acknowledged that the proposed algorithm will need to be validated, particularly in the reallife setting. Additionally, there are a number of potential barriers to using the proposed algorithm that need to be considered. Health care resources, such as physician time, access to spirometry, and measurement of eosinophil and FeNO levels, may be limited or unavailable; certain countries may not have multiple doses of ICS approved to allow for a stepwise reduction; and patients and physicians may be reluctant to change therapy if it is sufficient in terms of current disease control as opposed to avoiding future risks, such as side effects. Patients may also be resistant to changing therapy, as it will require more effort on their part and there is a potential risk of symptom worsening, especially if they end up having a phenotype that should be receiving ICS therapy.

\section{Conclusion}

It is now becoming evident that maintaining or initiating certain patients with COPD on ICS therapy solely on the basis of reducing their risk of exacerbations may not be necessary, particularly if they are maintained on effective dual bronchodilation with a LABA and LAMA. Clinicians need to carefully tailor therapy on a case-by-case basis, and determine who is an appropriate patient for ICS therapy, and if a patient is already on ICS therapy, how to carefully step down ICS therapy without doing harm. Currently, no clinical guidelines provide any recommendations regarding the safe withdrawal of ICS in patients with COPD. Accordingly, until this need is met, this perspective article proposes an algorithm for the stepwise withdrawal of ICS in real-life clinical practice based on the evidence available to date. 


\section{Step 1: review current management of COPD}

- Reassess device technique and adherence

- Risk reduction: advise smoking cessation, if necessary, and ensure that immunizations are up-to-date

- Optimize function: encourage physical exercise and ensure adequate nutrition

\section{Step 2: evaluate the risk-benefit profile of continuing ICS therapy}

- Consider patient history, symptoms (CAT, MMRC, or CCQ9), clinical features, and comorbidities

- Determine spirometry (pre- and post-bronchodilation with LABD held for $\geq 24$ hours)

- If available, consider sputum/blood eosinophil and FeNO levels

\begin{tabular}{|c|c|c|}
\hline Is it ACOS? & & \\
\hline $\begin{array}{c}\text { History or features } \\
\text { of asthma? }\end{array}$ & $\begin{array}{c}\text { Reversibility } \\
(>12 \% \text { and } 400 \mathrm{~mL}) ?\end{array}$ & $\begin{array}{l}\text { Meets the criteria of the } \\
2014 \text { GINA/GOLD } \\
\text { consensus statement? }\end{array}$ \\
\hline
\end{tabular}

\begin{tabular}{|l|l|}
\hline Frequent exacerbator? & $\geq 1$ hospitalizations for \\
exacerbations per year & severe exacerbations
\end{tabular}

Potential markers (optional):

Elevated sputum eosinophils (ie, $\geq 3 \%$ )?

Elevated blood
eosinophils
$\left(\mathrm{e}, \geq 300\right.$ cells $\left./ \mathrm{mm}^{3}\right) ?$

Elevated FeNO

(ie, $\geq 25 \mathrm{ppb}$ )?

\section{Continue ICS therapy}

Monitor for potential adverse events, particularly in high-risk patients (eg, elderly, pneumonia, tuberculosis, diabetes, osteoporosis, glaucoma/ cataracts)

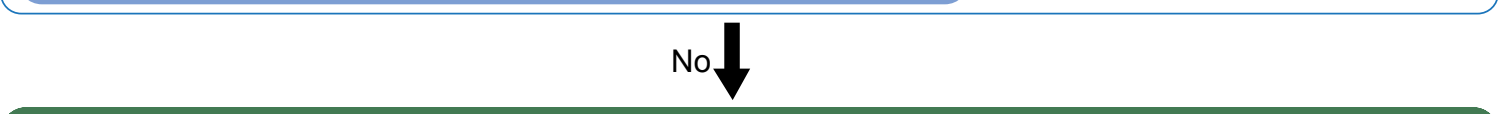

\section{Step 3: stepwise withdrawal of ICS}

- Initiate stepwise withdrawal of ICS depending on the patient's current ICS dose

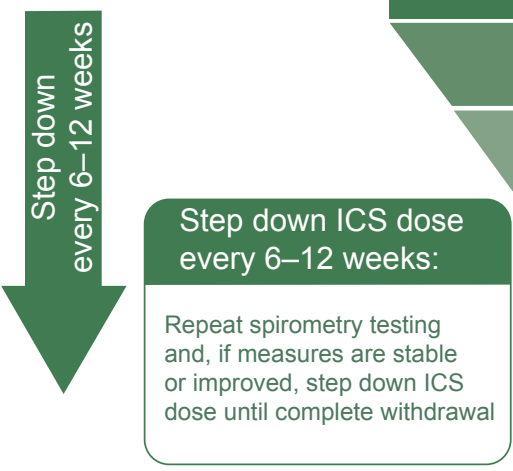

\section{What is the current ICS dose?}

At each step:

- Consider optimizing bronchodilation with LABA + LAMA, if the patient is symptomatic (see Step 4)

- Exercise caution in patients with risk factors for repeat exacerbations (eg, comorbidities/extrapulmonary manifestations, chronic bronchitis, increasing age)

\section{Step 4: optimize bronchodilation with LABA + LAMA}

- Once ICS is completely withdrawn (ie, at last step down from lowest dose of ICS available), consider optimizing bronchodilation with LABA + LAMA (ie, fixed-dose combination, if coverage is available, or separate devices), if not already done so in Step 3

- Choose a device that the patient is able to use effectively

\section{Step 5: follow-up}

- See patient every 3 months in the first year, followed by an annual review, if COPD is stable and exacerbation-free

Figure 2 A proposed step-by-step algorithm for safely withdrawing ICS from patients with COPD in real-life clinical practice.

Abbreviations: ACOS, asthma-COPD overlap syndrome; CAT, COPD Assessment Test; CCQ9, Chronic COPD Questionnaire; COPD, chronic obstructive pulmonary disease; FeNO, fractional exhaled nitric oxide; GINA, Global Initiative for Asthma; GOLD, Global Initiative for Chronic Obstructive Lung Disease; ICS, inhaled corticosteroids; LABA, long-acting $\beta_{2}$-agonist; LABD, long-acting bronchodilator; LAMA, long-acting muscarinic antagonist; mMRC, modified Medical Research Council Dyspnea Scale; ppb, parts per billion. 


\section{Acknowledgments}

Under Dr Kaplan's direction, medical writing assistance was provided by Marina Komolova, $\mathrm{PhD}$, of Sage Medica Inc.; this assistance was supported by Boehringer Ingelheim (Canada) Ltd., which had no role in the preparation of this manuscript.

\section{Disclosure}

AGK has received travel grants from AstraZeneca, Boehringer Ingelheim, and Novartis. He has been on the speaker's bureau for AstraZeneca, Boehringer Ingelheim, Griffols, Merck Frosst, Pfizer, Purdue, Novartis, Sanofi, and Takeda. He has been on advisory boards for AstraZeneca, Boehringer Ingelheim, Aerocrine, GSK, Pfizer, Purdue, Meda, and Novartis. The author (AGK) declares no conflicts of interest in this work, and has received no funding for preparing this manuscript.

\section{References}

1. Price D, Yawn B, Brusselle G, Rossi A. Risk-to-benefit ratio of inhaled corticosteroids in patients with COPD. Prim Care Respir J. 2013; 22(1):92-100.

2. Global Initiative for Chronic Obstructive Lung Disease (GOLD). Global Strategy for the Diagnosis, Management, and Prevention of Chronic Obstructive Pulmonary Disease; updated 2015. Available from: http:// www.goldcopd.org/uploads/users/files/GOLD_Report_2015.pdf. Accessed April 28, 2015.

3. O'Donnell DE, Hernandez P, Kaplan A, et al. Canadian Thoracic Society recommendations for management of chronic obstructive pulmonary disease - 2008 update - highlights for primary care. Can Respir J. 2008;15(Suppl A):1A-8A.

4. National Institute for Health and Care Excellence (NICE). Chronic Obstructive Pulmonary Disease: Management of Chronic Obstructive Pulmonary Disease in Adults in Primary and Secondary Care; 2010. Available from: https:/www.nice.org.uk/guidance/cg101/resources/ cg101-chronic-obstructive-pulmonary-disease-update-full-guideline2. Accessed April 29, 2015

5. Qaseem A, Wilt TJ, Weinberger SE, et al. Diagnosis and management of stable chronic obstructive pulmonary disease: a clinical practice guideline update from the American College of Physicians, American College of Chest Physicians, American Thoracic Society, and European Respiratory Society. Ann Intern Med. 2011;155(3): 179-191.

6. Miravitlles M, Calle M, Soler-Cataluña JJ. Clinical phenotypes of COPD: identification, definition and implications for guidelines. Arch Bronconeumol. 2012;48(3):86-98.

7. Kankaanranta H, Harju T, Kilpelainen M, et al. Diagnosis and pharmacotherapy of stable chronic obstructive pulmonary disease: the Finnish guidelines. Basic Clin Pharmacol Toxicol. 2015;116(4): 291-307.

8. Price D, West D, Brusselle G, et al. Management of COPD in the UK primary-care setting: an analysis of real-life prescribing patterns. Int J Chron Obstruct Pulmon Dis. 2014;9:889-904.

9. Koblizek V, Pecen L, Zatloukal J, et al. Real-life GOLD 2011 implementation: the management of COPD lacks correct classification and adequate treatment. PLoS One. 2014;9(11):e111078.

10. Vestbo J, Vogelmeier C, Small M, Higgins V. Understanding the GOLD 2011 strategy as applied to a real-world COPD population. Respir Med. 2014;108(5):729-736.

11. Suissa S, Barnes PJ. Inhaled corticosteroids in COPD: the case against. Eur Respir J. 2009;34(1):13-16.
12. Vogelmeier CF, Bateman ED, Pallante J, et al. Efficacy and safety of once-daily QVA149 compared with twice-daily salmeterol-fluticasone in patients with chronic obstructive pulmonary disease (ILLUMINATE): a randomised, double-blind, parallel group study. Lancet Respir Med. 2013;1(1):51-60

13. Yawn B, Kleerup E, Zhang J, Kianifard F, Williams J. Inhaled corticosteroid use and GOLD severity stage among patients with chronic obstructive pulmonary disease in different regions [abstract]. Am J Respir Crit Care Med. 2012;182:A2944.

14. Babu KS, Kastelik JA, Morjaria JB. Inhaled corticosteroids in chronic obstructive pulmonary disease: a pro-con perspective. $\mathrm{Br} \mathrm{J} \mathrm{Clin}$ Pharmacol. 2014;78(2):282-300.

15. Ernst P, Saad N, Suissa S. Inhaled corticosteroids in COPD: the clinical evidence. Eur Respir J. 2015;45(2):525-537.

16. Halpin DMG, Quint JK. The WISDOM of inhaled corticosteroids in COPD. Thorax. 2014;69(12):1071-1072.

17. Vestbo J, Sorensen T, Lange P, Brix A, Torre P, Viskum K. Long-term effect of inhaled budesonide in mild and moderate chronic obstructive pulmonary disease: a randomised controlled trial. Lancet. 1999;353(9167): 1819-1823.

18. Pauwels RA, Lofdahl CG, Laitinen LA, et al. Long-term treatment with inhaled budesonide in persons with mild chronic obstructive pulmonary disease who continue smoking. European Respiratory Society study on chronic obstructive pulmonary disease. N Engl J Med. 1999;340(25): 1948-1953.

19. Burge PS, Calverley PM, Jones PW, Spencer S, Anderson JA, Maslen TK. Randomised, double blind, placebo controlled study of fluticasone propionate in patients with moderate to severe chronic obstructive pulmonary disease: the ISOLDE trial. BMJ. 2000;320(7245): 1297-1303.

20. Sin DD, Tu JV. Inhaled corticosteroids and the risk of mortality and readmission in elderly patients with chronic obstructive pulmonary disease. Am J Respir Crit Care Med. 2001;164(4):580-584.

21. Szafranski W, Cukier A, Ramirez A, et al. Efficacy and safety of budesonide/formoterol in the management of chronic obstructive pulmonary disease. Eur Respir J. 2003;21(1):74-81.

22. Calverley PM, Anderson JA, Celli B, et al. Salmeterol and fluticasone propionate and survival in chronic obstructive pulmonary disease. N Engl J Med. 2007;356(8):775-789.

23. Suissa S, Ernst P, Vandemheen KL, Aaron SD. Methodological issues in therapeutic trials of COPD. Eur Respir J. 2008;31(5):927-933.

24. Wedzicha JA, Calverley PMA, Seemungal TA, Hagan G, Ansari Z, Stockley RA. The prevention of chronic obstructive pulmonary disease exacerbations by salmeterol/fluticasone propionate or tiotropium bromide. Am J Respir Crit Care Med. 2008;177(1):19-26.

25. Nannini LJ, Lasserson TJ, Poole P. Combined corticosteroid and longacting beta(2)-agonist in one inhaler versus long-acting beta2-agonists for chronic obstructive pulmonary disease. Cochrane Database Syst Rev. 2012;9:CD006829.

26. Vestbo J, Anderson J, Brook RD, et al. Study to understand mortality and morbidity in COPD (SUMMIT) [abstract]. Eur Respir J. 2015; 46(Suppl 59):OA3476.

27. Crim C, Calverley PMA, Anderson JA, et al. Pneumonia risk in COPD patients receiving inhaled corticosteroids alone or in combination: TORCH study results. Eur Respir J. 2009;34(3):641-647.

28. Suissa S, Patenaude V, Lapi F, Ernst P. Inhaled corticosteroids in COPD and the risk of serious pneumonia. Thorax. 2013;68(11): 1029-1036.

29. Yang IA, Clarke MS, Sim EH, Fong KM. Inhaled corticosteroids for stable chronic obstructive pulmonary disease. Cochrane Database Syst Rev. 2012;7:CD002991.

30. Kim JH, Park JS, Kim KH, Jeong HC, Kim EK, Lee JH. Inhaled corticosteroid is associated with an increased risk of TB in patients with COPD. Chest. 2013;143(4):1018-1024.

31. Brassard P, Suissa S, Kezouh A, Ernst P. Inhaled corticosteroids and risk of tuberculosis in patients with respiratory diseases. Am J Respir Crit Care Med. 2011;183(5):675-678. 
32. Cumming RG, Mitchell P, Leeder SR. Use of inhaled corticosteroids and the risk of cataracts. N Engl J Med. 1997;337(1):8-14.

33. Ernst P. Low-dose inhaled and nasal corticosteroid use and the risk of cataracts. Eur Respir J. 2006;27(6):1168-1174.

34. Loke YK, Cavallazzi R, Singh S. Risk of fractures with inhaled corticosteroids in COPD: systematic review and meta-analysis of randomised controlled trials and observational studies. Thorax. 2011;66(8): 699-708.

35. Suissa S, Kezouh A, Ernst P. Inhaled corticosteroids and the risks of diabetes onset and progression. Am J Med. 2010;123(11):1001-1006.

36. Hay CM, Spratt DI. Adrenal insufficiency in a woman secondary to standard-dose inhaled fluticasone propionate therapy. Endocrinol Diabetes Metab Case Rep. 2014;2014:130080.

37. Calverley PM. What to use INSTEAD of inhaled corticosteroids in COPD? Eur Respir J. 2014;44(6):1391-1393.

38. Suissa S, Coulombe J, Ernst P. Discontinuation of inhaled corticosteroids in COPD and the risk reduction of pneumonia. Chest. Epub 2015 Jun 25.

39. Jarad NA, Wedzicha JA, Burge PS, Calverley PM. An observational study of inhaled corticosteroid withdrawal in stable chronic obstructive pulmonary disease. ISOLDE Study Group. Respir Med. 1999; 93(3):161-166.

40. O'Brien A, Russo-Magno P, Karki A, et al. Effects of withdrawal of inhaled steroids in men with severe irreversible airflow obstruction Am J Respir Crit Care Med. 2001;164(3):365-371.

41. Schermer TR, Hendriks AJ, Chavannes NH, et al. Probability and determinants of relapse after discontinuation of inhaled corticosteroids in patients with COPD treated in general practice. Prim Care Respir J. 2004;13(1):48-55.

42. van der Valk P, Monninkhof E, van der Palen J, Zielhuis G, van Herwaarden C. Effect of discontinuation of inhaled corticosteroids in patients with chronic obstructive pulmonary disease: the COPE study. Am J Respir Crit Care Med. 2002;166(10):1358-1363.

43. Wouters EFM. Withdrawal of fluticasone propionate from combined salmeterol/fluticasone treatment in patients with COPD causes immediate and sustained disease deterioration: a randomised controlled trial. Thorax. 2005;60(6):480-487.

44. Choudhury AB, Dawson CM, Kilvington HE, et al. Withdrawal of inhaled corticosteroids in people with COPD in primary care: a randomised controlled trial. Respir Res. 2007;8:93.

45. Nadeem NJ, Taylor SJC, Eldridge SM. Withdrawal of inhaled corticosteroids in individuals with COPD - a systematic review and comment on trial methodology. Respir Res. 2011;12:107.

46. Magnussen H, Watz H, Kirsten A, et al. Stepwise withdrawal of inhaled corticosteroids in COPD patients receiving dual bronchodilation: WISDOM study design and rationale. Respir Med. 2014;108(4):593-599.

47. Rossi A, Guerriero M, Corrado A, OPTIMO/AIPO Study Group. Withdrawal of inhaled corticosteroids can be safe in COPD patients at low risk of exacerbation: a real-life study on the appropriateness of treatment in moderate COPD patients (OPTIMO). Respir Res. 2014; $15: 77$.

48. Rossi A, van der Molen T, Olmo Rd, et al. INSTEAD: a randomised switch trial of indacaterol versus salmeterol/fluticasone in moderate COPD. Eur Respir J. 2014;44(6):1548-1556.

49. Leuppi JD, Salome CM, Jenkins CR, et al. Predictive markers of asthma exacerbation during stepwise dose reduction of inhaled corticosteroids. Am J Respir Crit Care Med. 2001;163(2):406-412.

50. Magnussen H, Disse B, Rodriguez-Roisin R, et al. Withdrawal of inhaled glucocorticoids and exacerbations of COPD. N Engl J Med. 2014; 371(14):1285-1294.

51. Magnussen H, Tetzlaff K, Calverley PM. Inhaled glucocorticoids and COPD exacerbations. $N$ Engl J Med. 2015;372(1):93-94.

52. Alcazar Navarrete B, Casanova C, Miravitlles M, et al. "Correct use of inhaled corticosteroids in chronic obstructive pulmonary disease": a consensus document. Arch Bronconeumol. 2015;51(4):193-198.

53. Braman SS. The chronic obstructive pulmonary disease-asthma overlap syndrome. Allergy Asthma Proc. 2015;36(1):11-18.
54. Bujarski S, Parulekar AD, Sharafkhaneh A, Hanania NA. The Asthma COPD Overlap Syndrome (ACOS). Curr Allergy Asthma Rep. 2015; 15(3):1-9.

55. Louie S, Zeki AA, Schivo M, et al. The asthma-chronic obstructive pulmonary disease overlap syndrome: pharmacotherapeutic considerations. Expert Rev Clin Pharmacol. 2013;6(2):197-219.

56. Global Initiative for Asthma (GINA), Global Initiative for Chronic Obstructive Lung Disease (GOLD). Diagnosis of Diseases of Chronic Airflow Limitation: Asthma, COPD and Asthma-COPD Overlap Syndrome (ACOS); 2015. Available from: http://www.goldcopd. org/uploads/users/files/AsthmaCOPDOverlap.pdf. Accessed May 4, 2015.

57. Gershon AS, Campitelli MA, Croxford R, et al. Combination longacting $\beta$-agonists and inhaled corticosteroids compared with long-acting $\beta$-agonists alone in older adults with chronic obstructive pulmonary disease. JAMA. 2014;312(11):1114-1121.

58. Hurst JR, Vestbo J, Anzueto A, et al. Susceptibility to exacerbation in chronic obstructive pulmonary disease. $N$ Engl J Med. 2010;363(12): $1128-1138$.

59. Agusti A, Fabbri L. Inhaled steroids in COPD: when should they be used? Lancet Respir Med. 2014;2(11):869-871.

60. Beeh KM, Derom E, Echave-Sustaeta J, et al. ENERGITO: efficacy and safety of once-daily combined tiotropium + olodaterol versus twice-daily combined fluticasone propionate + salmeterol [abstract] Eur Respir J. 2015;46(Suppl 59):PA4366.

61. Bafadhel M, McKenna S, Terry S, et al. Acute exacerbations of chronic obstructive pulmonary disease: identification of biologic clusters and their biomarkers. Am J Respir Crit Care Med. 2011;184(6):662-671.

62. Liesker JJ, Bathoorn E, Postma DS, Vonk JM, Timens W, Kerstjens HA. Sputum inflammation predicts exacerbations after cessation of inhaled corticosteroids in COPD. Respir Med. 2011;105(12):1853-1860.

63. Pascoe S, Locantore N, Dransfield MT, Barnes NC, Pavord ID. Blood eosinophil counts, exacerbations, and response to the addition of inhaled fluticasone furoate to vilanterol in patients with chronic obstructive pulmonary disease: a secondary analysis of data from two parallel randomised controlled trials. Lancet Respir Med. 2015;3(6):435-442.

64. Siva R, Green RH, Brightling CE, et al. Eosinophilic airway inflammation and exacerbations of COPD: a randomised controlled trial. Eur Respir J. 2007;29(5):906-913.

65. Wedzicha JA, Price D, Mezzi K, Fogel R, Banerji D. QVA149 compared with salmeterol/fluticasone (SFC) on exacerbations and its correlation with baseline blood eosinophils: a pooled analysis of LANTERN and ILLUMINATE [abstract]. Eur Respir J. 2015;46(Suppl 59): PA1005.

66. Siddiqui SH, Guasconi A, Vestbo J, et al. Blood eosinophils: a biomarker of response to extrafine beclomethasone/formoterol in chronic obstructive pulmonary disease. Am J Respir Crit Care Med. 2015;192(4): 523-525.

67. Vedel-Krogh S, Nielsen SF, Lange P, Vestbo J, Nordestgard BG. Blood eosinophils and exacerbations in chronic obstructive pulmonary disease: the Copenhagen General Population Study [abstract]. Eur Respir J. 2015; 46(Suppl 59):OA2934.

68. Antus B, Barta I, Horvath I, Csiszer E. Relationship between exhaled nitric oxide and treatment response in COPD patients with exacerbations. Respirology. 2010;15(3):472-477.

69. Soter S, Barta I, Antus B. Predicting sputum eosinophilia in exacerbations of COPD using exhaled nitric oxide. Inflammation. 2013;36(5): $1178-1185$.

70. Bjermer L, Alving K, Diamant Z, et al. Current evidence and future research needs for FeNO measurement in respiratory diseases. Respir Med. 2014;108(6):830-841.

71. Dweik RA, Boggs PB, Erzurum SC, et al. An official ATS clinical practice guideline: interpretation of exhaled nitric oxide levels (FENO) for clinical applications. Am J Respir Crit Care Med. 2011;184(5): 602-615.

72. Barnes PJ. Inhaled corticosteroids. Pharmaceuticals. 2010;3(3): 514-540. 
73. Lung Health Study Research Group. Effect of inhaled triamcinolone on the decline in pulmonary function in chronic obstructive pulmonary disease. N Engl J Med. 2000;343(26):1902-1909.

74. Alsaeedi A, Sin DD, McAlister FA. The effects of inhaled corticosteroids in chronic obstructive pulmonary disease: a systematic review of randomized placebo-controlled trials. Am J Med. 2002;113(1): 59-65.

75. Aaron SD, Vandemheen KL, Fergusson D, et al. Tiotropium in combination with placebo, salmeterol, or fluticasone-salmeterol for treatment of chronic obstructive pulmonary disease: a randomized trial. Ann Intern Med. 2007;146(8):545-555.
76. Welte T, Miravitlles M, Hernandez P, et al. Efficacy and tolerability of budesonide/formoterol added to tiotropium in patients with chronic obstructive pulmonary disease. Am J Respir Crit Care Med. 2009;180(8):741-750.

\section{Publish your work in this journal}

The International Journal of COPD is an international, peer-reviewed journal of therapeutics and pharmacology focusing on concise rapid reporting of clinical studies and reviews in COPD. Special focus is given to the pathophysiological processes underlying the disease, intervention programs, patient focused education, and self management protocols.

\section{Dovepress}

This journal is indexed on PubMed Central, MedLine and CAS. The manuscript management system is completely online and includes a very quick and fair peer-review system, which is all easy to use. Visit http://www.dovepress.com/testimonials.php to read real quotes from published authors.

\footnotetext{
Submit your manuscript here: http://www.dovepress.com/international-journal-of-chronic-obstructive-pulmonary-disease-journal
} 